\title{
Sequence variation does not confound the measurement of plasma PfHRP2 concentration in African children presenting with severe malaria
}

Thiranut Ramutton ${ }^{1}$, Ilse CE Hendriksen²,3, Juliet Mwanga-Amumpaire ${ }^{4}$, George Mtove ${ }^{5}$, Rasaq Olaosebikan 6 , Antoinette K Tshefu' ${ }^{7}$, Marie A Onyamboko ${ }^{7}$, Corine Karema ${ }^{8}$, Kathryn Maitland ${ }^{9}$, Ermelinda Gomes ${ }^{10}$, Samwel Gesase ${ }^{11}$, Hugh Reyburn ${ }^{12}$, Kamolrat Silamut ${ }^{2}$, Kesinee Chotivanich ${ }^{2}$, Kamoltip Promnares ${ }^{13,14}$, Caterina I Fanello ${ }^{2,3}$, Lorenz von Seidlein ${ }^{15}$, Nicholas PJ Day ${ }^{2,3}$, Nicholas J White ${ }^{2,3}$, Arjen M Dondorp ${ }^{2,3}$, Mallika Imwong $2,16^{*}$ and Charles J Woodrow ${ }^{2,3^{*}}$

\begin{abstract}
Background: Plasmodium falciparum histidine-rich protein PFHRP2 measurement is used widely for diagnosis, and more recently for severity assessment in falciparum malaria. The Pfhrp2 gene is highly polymorphic, with deletion of the entire gene reported in both laboratory and field isolates. These issues potentially confound the interpretation of PFHRP2 measurements.

Methods: Studies designed to detect deletion of Pfhrp2 and its paralog Pfhrp3 were undertaken with samples from patients in seven countries contributing to the largest hospital-based severe malaria trial (AQUAMAT). The quantitative relationship between sequence polymorphism and PFHRP2 plasma concentration was examined in samples from selected sites in Mozambique and Tanzania.

Results: There was no evidence for deletion of either Pfhrp2 or Pfhrp3 in the 77 samples with lowest PFHRP2 plasma concentrations across the seven countries. Pfhrp2 sequence diversity was very high with no haplotypes shared among 66 samples sequenced. There was no correlation between Pfhrp2 sequence length or repeat type and PFHRP2 plasma concentration.

Conclusions: These findings indicate that sequence polymorphism is not a significant cause of variation in PFHRP2 concentration in plasma samples from African children. This justifies the further development of plasma PFHRP2 concentration as a method for assessing African children who may have severe falciparum malaria. The data also add to the existing evidence base supporting the use of rapid diagnostic tests based on PFHRP2 detection.
\end{abstract}

Keywords: Malaria, Falciparum, Severe, Africa, Histidine-rich protein, Tandem repeat

\section{Background}

The Plasmodium falciparum histidine-rich proteins PFHRP2 and PFHRP3 [1] are soluble proteins containing highly antigenic tandem repeat sequences [2] and are produced in large quantities during the asexual blood stage of the P. falciparum lifecycle [3] where

\footnotetext{
* Correspondence: noi@tropmedres.ac; charlie@tropmedres.ac

${ }^{2}$ Mahidol-Oxford Tropical Medicine Research Unit, Faculty of Tropical

Medicine, Mahidol University, Bangkok, Thailand

${ }^{16}$ Department of Molecular Tropical Medicine and Genetics, Faculty of

Tropical Medicine, Mahidol University, Bangkok, Thailand

Full list of author information is available at the end of the article
}

their concentration represents a dynamic equilibrium [4]. Orthologs are not found in other species of human malaria [5]. Antibody detection of PFHRP2 (which also picks up PFHRP3) is, therefore, a sensitive method for the rapid diagnosis of $P$. falciparum malaria using whole blood [6], as well as an in vitro drug sensitivity readout that has found increasing use in recent years [7]. PFHRP2 is also released into plasma, where its concentration reflects the extent of current and previous cycle parasite sequestration, a process considered critical to the pathology of severe malaria [8]. 
Since the initial description of these histidine-rich proteins more than two decades ago [1,9], their physiological role in the lifecycle of $P$. falciparum has been subject to a number of lines of investigation, with the focus of most attention on haem polymerization [10]. A degree of redundancy exists with parasites lacking one or both of these proteins still able to propagate in asexual stage culture and complete the entire parasite life cycle [11-13]. Nevertheless, classical falciparum genetic crosses in which one parent had a deletion of Pfhrp3 demonstrated complete [14] or partial [15] bias towards Pfhrp3 inheritance (although the cross-over interval was not fine enough to attribute enhanced fitness specifically to Pfhrp3 as opposed to nearby genes). Perhaps surprisingly, Pfhrp2 did not show inheritance bias in the HB3 $\mathrm{x}$ Dd2 cross [15]; low-level transcription in the HB3 parent [16] could potentially explain this in part or in whole.

In contrast to these studies on cultured isolates, prior to 2010 no field isolates had been reported which lacked either Pfhrp2 or Pfhrp3. However, relatively recent evidence of significant numbers of parasites with deletion of one or both genes has emerged in the Peruvian Amazon [17,18], generating concerns over the reliability of PFHRP2-based rapid diagnostic tests (RDTs) in this region. There has been little evidence that deletion of either gene occurs to a significant degree in Africa. This may reflect both the true rarity of the event (given the predicted deleterious effect on fitness), along with the higher multiplicities of infection found in high transmission settings. It is therefore concerning that isolates from Mali lacking Pfhrp2 have now been described [19].

Both Pfhrp2 and Pfhrp3 also exhibit extensive insertiondeletion polymorphism, and the potential for this to reduce the accuracy of RDTs has been examined at national [20] and global scales $[21,22]$. However, whether sequence variation is an important confounder in the assessment of plasma concentration, and hence disease severity, has not been studied. This study examined the relationship between Pfhrp2 sequence and plasma PFHRP2 concentration in samples derived from a large group of African children treated for severe malaria in the AQUAMAT trial [23].

\section{Methods}

A PCR-based approach was used to answer a number of related questions. First, Pfhrp 2 deletions were sought in parasites from patients admitted with a diagnosis of severe malaria but who had very low or undetectable plasma PFHRP2 levels by ELISA. Deletions in Pfhrp3 were also checked since by cross-reacting with PFHRP2, the less abundant PFHRP3 allows RDTs to retain some sensitivity even when Pfhrp2 deletions are present. Finally, the relationship between Pfhrp 2 exon 2 length and repeat structure and plasma concentration was explored.

\section{Samples}

Samples were obtained from children enrolled in the AQUAMAT trial, a large multinational trial comparing quinine and artesunate for the treatment of severe malaria in African children undertaken between October 2005 and July 2010 and described in detail elsewhere [23]. Children were included if they showed signs of severe malaria (defined by clinical criteria) and had a positive $P$. falciparum lactate dehydrogenase RDT. Patients were excluded if treated parenterally for more than 24 hours before admission. Patients were randomized to treatment with either parenteral artesunate or quinine. Baseline blood samples included a peripheral blood slide. Slide reading was performed by microscopists at the Mahidol-Oxford Tropical Medicine Research Unit and parasitaemia/ $\mu$ l was calculated from thin film (count/1,000 RBCx125.6xHct) or thick film (count/200 WBCx40). Dried whole blood spots were used for molecular studies. EDTA blood for plasma PFHRP2 measurement was received from nine of the 11 AQUAMAT research sites in seven countries (Table 1).

DNA samples from established $P$. falciparum lines (K1, Dd2, 3d7) were provided by MR4 and used to control Pfhrp 2 and Pfhrp3 PCR results. A number of samples from within Asia were also tested to validate methodology, confirming the finding [22] that Pfhrp2 exon 2 sequences from African samples are longer than those from Cambodia, as they have substantially more type 7 repeats. To reduce the potential confounding effect of differing clinical characteristics in patients recruited in different sites, the relationship between Pfhrp 2 sequence and plasma concentration was focused on sample sets from Mozambique and Tanzania (Teule).

Appropriate ethical approvals were granted by the Oxford Tropical Research Ethics Committee, the Ethics Committee of the Faculty of Tropical Medicine, Mahidol University and the individual study site countries' ethical review boards.

\begin{tabular}{|c|c|c|c|}
\hline Country & Site & Available samples & Samples tested (\%) \\
\hline $\mathrm{DRC}$ & Kinshasa & 420 & $6(1.43)$ \\
\hline The Gambia & Banjul & 60 & $2(3.33)$ \\
\hline Kenya & Kilifi & 378 & $12(3.17)$ \\
\hline Mozambique & Beira & 659 & $19(2.88)$ \\
\hline \multirow[t]{2}{*}{ Rwanda } & Kigali & 170 & $10(5.88)$ \\
\hline & Nyanza & 111 & $5(4.50)$ \\
\hline \multirow[t]{2}{*}{ Tanzania } & Korogwe & 534 & $3(0.56)$ \\
\hline & Teule & 901 & $15(1.66)$ \\
\hline Uganda & Mbarare & 593 & $5(0.84)$ \\
\hline Total & & 3826 & 77 (1.98) \\
\hline
\end{tabular}




\section{Laboratory techniques}

Parasite DNA from dried blood spots was extracted via the QIAmp DNA Mini kit using the standard protocol and stored at $-20^{\circ} \mathrm{C}$ until use. For both Pfhrp 2 and Pfhrp3, a semi-nested PCR approach was used involving identical primers and conditions to those already described by Baker et al. [21]. These primers anneal to the conserved end regions of exon 2 of Pfhrp 2 and Pfhrp3, with the intervening sequence encompassing the variable histidinerich repeats of these genes. To confirm $P$. falciparum infection in Pfhrp2-negative samples or those with very weak bands, a fully nested PCR Plasmodium species detection approach was employed using specific oligonucleotide primers to amplify a segment of ssrRNA using published primers and conditions [24]. For Pfhrp2 sequencing, amplified DNA products were purified using the Favorgen Gel/PCR purification kit according to the manufacturer's instructions. DNA concentrations were estimated by agarose gel electrophoresis and samples sent for sequencing (using the Pfhrp 2 internal forward primer [21]) at Macrogen, Seoul, South Korea.

Plasma PFHRP2 was measured in freeze-thawed EDTA plasma samples according to standard techniques [25]. In brief a commercial sandwich ELISA kit (Celisa, Cellabs, Sydney, Australia) was used according to the manufacturer's instructions with minor modifications and blinded to patient outcomes [8]. Pooled reference plasma was derived from 20 subjects with parasitaemia $>200,000 / \mu \mathrm{l}$ and used to construct standard curves.

\section{Statistics}

Comparisons of Pfhrp2 exon 2 length and repeat number were undertaken by the Mann-Whitney test in GraphPad Prism.

\section{Results}

Assessment of possible deletion of Pfhrp2 or Pfhrp3

Plasma PFHRP2 was measured in 3,826 of the 5,426 children with pLDH-RDT-confirmed falciparum malaria included in the AQUAMAT trial. The 80 samples associated with lowest plasma PFHRP2 levels yielded 77 blood spots which were analysed using a semiquantitative approach for possible deletions in Pfhrp 2 or Pfhrp3 (Table 1, Figure 1a). These samples had a median parasitaemia of $9,043 / \mu$ l (compared to $79,397 / \mu$ l for the whole dataset). PCR for Pfhrp 2 revealed bands of the anticipated size in 70 cases; in seven cases (median parasitaemia $3,040 / \mu \mathrm{l}$ ) no band could be obtained despite repeated attempts. In all these Pfhrp2-negative cases, the sample also had negative or very weak bands for Pfhrp3 as well as species identification, indicating that DNA content of the sample was at or below the threshold of detection. In an analogous manner, PCR for Pfhrp3 was found to be positive in 67 samples, and was only negative (ten cases) when the other two reactions were negative or produced very dilute products.

\section{Sequence polymorphism in Pfhrp2}

In order to explore the relationship between Pfhrp 2 sequence and plasma concentration, the aim was to obtain
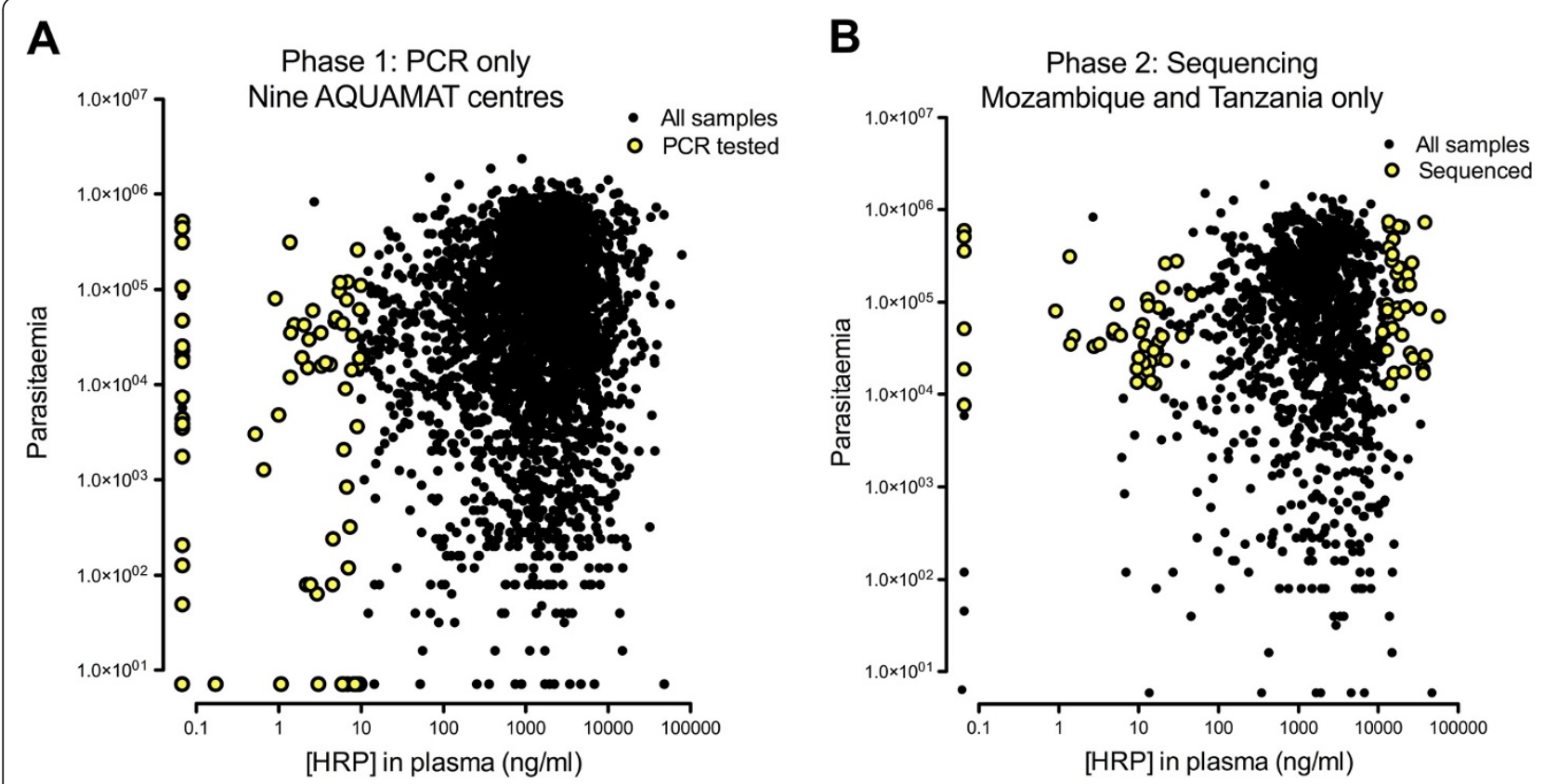

Figure 1 PfHRP2 levels and parasitaemias for samples examined. A: samples subjected to PCR for Pfhrp2 and Pfhrp3 across all relevant AQUAMAT centres; B: samples sequenced from Mozambique and Tanzania (Teule site). 
80 sequences from patients in Tanzania (Teule) and Mozambique associated with extreme values of plasma PFHRP2 (40 high, 40 low) but with relatively high peripheral parasitaemias (greater than $10,000 / \mu \mathrm{l}$ ) and hence likely to produce reliable material for sequencing (Figure 1b). Twenty-six clean PCR products suitable for sequencing had already been obtained from these two sites in the first phase of testing samples with low PFHRP2 levels. An additional 62 (22 low PFHRP2, 40 high) samples therefore underwent DNA extraction and Pfhrp2 PCR; all gave bands with no evidence of Pfhrp2 deletion. After sequencing, clear and complete exon 2 sequences were available in 34 samples from Mozambique and 32 from Tanzania. Across these 66 samples, 37 patients had low PFHRP2 levels (median (range) $=10.9 \mathrm{ng} / \mathrm{ml}($ undetectable -46.1$))$ while 29 had high PFHRP2 levels $(18,017 \mathrm{ng} / \mathrm{ml}(11,289-56,818))$.

As expected from the gel electrophoresis results, and consistent with previous findings [20-22], PCR products were highly variable in length, as well as the numbers and types of repeat (Figure 2a). For Mozambique the median Pfhrp2 exon 2 PCR product length was 741 bp (range 627-816) and for Tanzania 759 (range 651-876) ( $\mathrm{p}=0.12$; Table 2). Of the repeat types described by Baker et al., types 2 (AHHAHHAAD) and 7 (AHHAAD) were the most prominent (Figure $2 \mathrm{~b}$ ), constituting more than half of each sequence; these were also the only repeat types observed in all samples. All the other repeats documented were fewer in number (no more than six of any repeat in any sample). There was no significant difference in the number of type 2 , type 7 or any other repeat between Mozambique and Tanzania (Figure 2b, Table 2) and the two datasets were pooled to explore the possible association between Pfhrp 2 polymorphism and plasma levels.

Sequence length, number of type 2 repeats and number of type 7 repeats did not correlate with PFHRP2 plasma concentration when expressed as a continuous variable (Figure 3a). There was also no significant difference in these sequence properties between low and high categories of PFHRP2 (Figure 3b).

\section{Discussion}

PFHRP2 is released into the circulating plasma $[8,26-$ 28] where it persists for several days [29]. Because of the exponential rise in parasitaemia that occurs during the development of $P$. falciparum in the blood, in whole blood a large portion of PFHRP2 is located within asexual parasites [27], and whole-blood PFHRP2 concentrations correlate, therefore, with peripheral blood parasitaemia. By contrast, plasma PFHRP2 provides a summative picture of previous cycles of growth that reflects sequestered parasite biomass rather than circulating biomass [8]. Plasma PFHRP2 measurement can therefore potentially be applied in the management of severely ill patients in high transmission settings who may be ill because of malaria or alternatively have another severe illness, with malaria parasitaemia an incidental finding [30]. Post-mortem reveals that $25 \%$ of patients thought to have died of severe malaria have other serious pathology [31]. Confident differentiation of severe malaria from other pathologies where the prevalence of malaria parasitaemia is high is very difficult [30]; observation of malarial retinopathy improves the accuracy of diagnosis for cerebral malaria [32], but requires skill and training and is rarely achievable in practice outside centres of excellence. Since plasma PFHRP2 derives from sequestered parasites that are critical to the pathology of severe malaria, it has potential to differentiate 'true' severe malaria from alternative illnesses in parasitaemic patients, as well as provide an independent marker of prognostic significance in severe malaria [8]. Plasma PFHRP2 levels were found to be
A

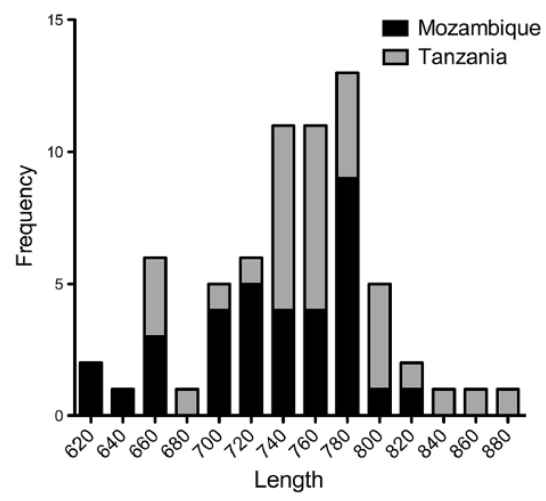

B

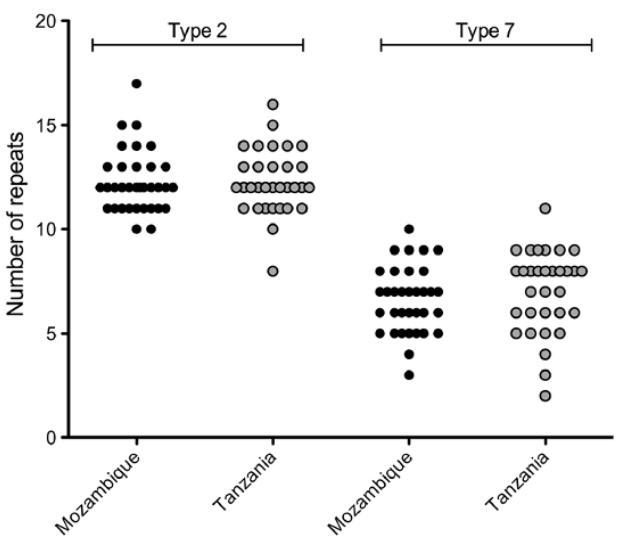

Figure 2 Pfhrp2 exon 2 length and repeat numbers according to country. A: frequency of each exon size (bin width of 20 bp); B: numbers of type 2 and 7 repeats in each sample. 
Table 2 Pfhrp2 exon 2 length and repeat polymorphism data by country

\begin{tabular}{lllll}
\hline Population & Mozambique & Tanzania (Teule) & Combined & \\
Total number & 34 & 32 & 66 & $751.5(627-876)$ \\
Length: median (range) & $741(627-816)$ & $759(651-876)$ & 66 & \\
Haplotypes & 34 & 32 & $12(8-17)$ \\
Repeats & & & $7(2-11)$ & 0.12 \\
Type 2 & $12(10-17)$ & $8(2-11)$ & 0.70 \\
Type 7 & $7(3-10)$ & 0.22 \\
\hline
\end{tabular}

The types and numbers of repeats for each sequence were examined using the repeat structure described by Baker et al. [21].

higher in patients with severe falciparum malaria compared to uncomplicated malaria in Indonesia [33] and Thailand [8] although studies in Kenya [34] and Papua New Guinea [35] did not find a significant difference. Explanations for these apparently discrepant findings include different classifications of disease severity as well as differences in the intensity of transmission. A particular problem in these studies, and in other studies of severe malaria is the classification of children with severe anaemia and low parasitaemia as having "severe malaria", many of whom have chronic anaemia and incidental parasitaemia. These patients do not have large numbers of sequestered parasites and so do not have high plasma PFHRP2 concentrations.

The antibodies present in PFHRP2 RDT kits detect the repetitive histidine-rich repeats encoded by exon 2 of Pfhrp2 (and Pfhrp3) [2,36]. This is a strength of PFHRP2-based diagnosis, since the antigen sequence appears many times within the protein and one protein can be bound by several antibody molecules potentially leading to amplification of signal and high assay sensitivity. However, the nature of the antigen detected optimally by each RDT clearly differs between kits [2,36].
The possibility that this might impair the accuracy of RDTs was reflected for a time by a concern that certain patterns of repeat polymorphism (relating to numbers of type 2 and type 7 repeats) were associated with lower levels of detection, based on a semi-quantitative analysis of kit sensitivity [21]. Subsequent work has not supported this possibility and the performance of a range of RDTs now appears unlikely to be confounded by sequence polymorphisms [22].

This study aimed to address the concern that quantification of plasma PFHRP2 might be confounded by sequence polymorphism in terms of type and number of histidine-containing repeats in PFHRP2. Among parasites from Mozambique and Tanzania, a diverse pattern of repeat types was observed consistent with previous studies from a wide range of African countries [20-22]. Within this variation, there was no relationship between the number of repeats observed, or overall sequence length, and plasma PFHRP2 level, mirroring the semiquantitative findings from studies examining rapid diagnostic tests [22]. These findings do not support the idea that sequence polymorphism has a substantial influence on ELISA-based PFHRP2 quantitation in African

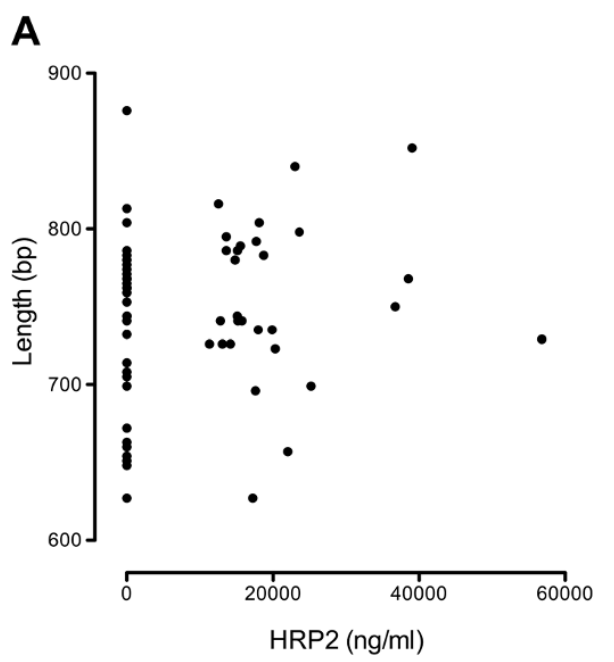

B

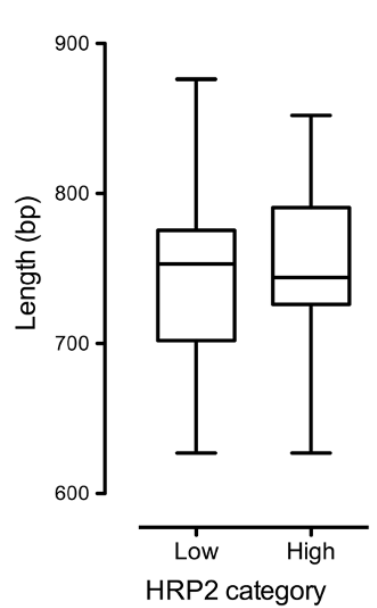

Figure 3 Relationship between Pfhrp2 exon 2 length and plasma level. A: individual samples; B: categorized by PFHRP2 level. 
samples. The results presented here, along with existing data that in Southeast Asian adult plasma PFHRP2 correlates well with severity of disease $[8,33]$, provide support for further work aimed at developing measurement of plasma PFHRP2 as an aid to the diagnosis and the management of severely ill African children [25].

Previous reports of field isolates with deletion of one or both of these genes examined samples originating in areas with generally low multiplicity of infection (MOI) $[17,18]$, or focused on samples from individuals with no or few symptoms of malaria and hence likely to have lower MOI [19]. In this survey of around 80 selected parasite samples from patients admitted with a diagnosis of severe malaria but with very low PFHRP2 plasma levels across a number of African countries, there was no evidence for deletion of either Pfhrp2 or Pfhrp3. Multiplicity of infection was not measured, although it is likely that a significant proportion of these samples contained single infections, since around 10\% contained insufficient DNA to produce a PCR product in two independent reactions. It is also worth noting that the median asexual parasitaemia in this subgroup was about 9,000 parasites per $\mu \mathrm{l}$, a figure similar to that associated with false-negative RDTs in the recently published study from Mali. The findings therefore provide a degree of reassurance regarding the prevalence of Pfhrp 2 and Pfhrp3 deletion across the sites examined.

\section{Conclusion}

PFHRP2 sequence variation in parasites causing severe malaria in Africa does not confound the quantification of PFHRP2 antigen in plasma. This is a key element in the development of plasma PFHRP2 concentration measurement as a method for assessing African children who may have severe falciparum malaria. The evidence supports the concept that sequestered parasite biomass is the major cause of variation of PFHRP2 concentration in patient samples.

\section{Competing interests}

The authors declare that they have no competing interests.

\section{Authors' contributions}

TR and KP carried out the molecular biology. IH, JM-A, GM, RO, AT, MO, CK, KM, EG, SG, LVS and HR were responsible for clinical data. KS and KC were responsible for parasitological data. $T R, I H, C I F, N W, N D, A D, M I$ and $C W$ participated in the design of the study. TR, KP, MI and CW were responsible for data analysis and management. TR, MI and CW drafted the manuscript. All authors read and approved the final manuscript.

\section{Acknowledgements}

The study was supported by grants 076908 and 082541 from the Wellcome Trust, and was coordinated as part of the Wellcome Trust Mahidol University Oxford Tropical Medicine Research Programme funded by the Wellcome Trust of Great Britain.

\section{Author details}

${ }^{1}$ Department of Clinical Tropical Medicine, Faculty of Tropical Medicine, Mahidol University, Bangkok, Thailand. ${ }^{2}$ Mahidol-Oxford Tropical Medicine Research Unit, Faculty of Tropical Medicine, Mahidol University, Bangkok,
Thailand. ${ }^{3}$ Centre for Clinical Vaccinology and Tropical Medicine, Churchill Hospital, University of Oxford, Oxford, UK. ${ }^{4}$ Mbarara University of Science and Technology and Epicentre Research Base, Mbarara, Uganda. ${ }^{5}$ National Institute for Medical Research, Amani Centre, Tanga, Tanzania. ${ }^{6} \mathrm{MRC}$ laboratories, Banjul, The Gambia. ${ }^{7}$ Kinshasa School of Public Health, Kingasani Research Centre, Kinshasa, DRC. ${ }^{8}$ Malaria Control Program, Ministry of Health, Kigali, Rwanda. ${ }^{9}$ Kenya Medical Research Institute (KEMRI)-Wellcome Trust Research Programme, Kilifi, Kenya. ${ }^{10}$ Hospital Central da Beira, Beira, Mozambique. ${ }^{11}$ National Institute for Medical Research, Korogwe Research Laboratory, Tanga, Tanzania. ${ }^{12}$ London School of Tropical Medicine and Hygiene, London, UK. ${ }^{13}$ Department of Molecular Biotechnology and Bioinformatics, Faculty of Science, Prince of Songkla University, Hat Yai, Songkhla 90112, Thailand. ${ }^{14}$ Center for Genomics and Bioinformatics Research, Faculty of Science, Prince of Songkla University, Hat Yai, Songkhla, 90112, Thailand. ${ }^{15}$ Menzies School of Health Research, Casuarina, NT, Australia. ${ }^{16}$ Department of Molecular Tropical Medicine and Genetics, Faculty of Tropical Medicine, Mahidol University, Bangkok, Thailand.

Received: 23 May 2012 Accepted: 13 August 2012

Published: 16 August 2012

\section{References}

1. Leech JH, Barnwell JW, Aikawa M, Miller LH, Howard RJ: Plasmodium falciparum malaria: association of knobs on the surface of infected erythrocytes with a histidine-rich protein and the erythrocyte skeleton. J Cell Biol 1984, 98:1256-1264

2. Lee N, Baker J, Andrews KT, Gatton ML, Bell D, Cheng Q, McCarthy J: Effect of sequence variation in Plasmodium falciparum histidine- rich protein 2 on binding of specific monoclonal antibodies: Implications for rapid diagnostic tests for malaria. J Clin Microbiol 2006, 44:2773-2778.

3. Otto TD, Wilinski D, Assefa S, Keane TM, Sarry LR, Bohme U, Lemieux J, Barrell B, Pain A, Berriman M, Newbold C, Llinas M: New insights into the blood-stage transcriptome of Plasmodium falciparum using RNA-Seq. Mol Microbiol 2010, 76:12-24.

4. Marquart L, Butterworth A, McCarthy JS, Gatton ML: Modelling the dynamics of Plasmodium falciparum histidine-rich protein 2 in human malaria to better understand malaria rapid diagnostic test performance. Malar J 2012, 11:74.

5. Rock EP, Marsh K, Saul AJ, Wellems TE, Taylor DW, Maloy WL, Howard RJ: Comparative analysis of the Plasmodium falciparum histidine-rich proteins HRP-I, HRP-II and HRP-III in malaria parasites of diverse origin. Parasitology 1987, 95(Pt 2):209-227.

6. Shiff CJ, Premji Z, Minjas JN: The rapid manual ParaSight-F test. A new diagnostic tool for Plasmodium falciparum infection. Trans $R$ Soc Trop Med Hyg 1993, 87:646-648.

7. Noedl H, Wernsdorfer WH, Miller RS, Wongsrichanalai C: Histidine-rich protein II: a novel approach to malaria drug sensitivity testing. Antimicrob Agents Chemother 2002, 46:1658-1664.

8. Dondorp AM, Desakorn V, Pongtavornpinyo W, Sahassananda D, Silamut K, Chotivanich K, Newton PN, Pitisuttithum P, Smithyman AM, White NJ, Day NP: Estimation of the total parasite biomass in acute falciparum malaria from plasma PfHRP2. PLoS Med 2005, 2:e204.

9. Wellems TE, Howard RJ: Homologous genes encode two distinct histidine-rich proteins in a cloned isolate of Plasmodium falciparum. Proc Natl Acad Sci U S A 1986, 83:6065-6069.

10. Sullivan DJ Jr, Gluzman IY, Goldberg DE: Plasmodium hemozoin formation mediated by histidine-rich proteins. Science 1996, 271:219-222.

11. Pologe $L G$, Ravetch JV: Large deletions result from breakage and healing of $P$. falciparum chromosomes. Cell 1988, 55:869-874.

12. Kemp DJ, Thompson JK, Walliker D, Corcoran LM: Molecular karyotype of Plasmodium falciparum: conserved linkage groups and expendable histidine-rich protein genes. Proc Natl Acad Sci U S A 1987, 84(21):7672-7676

13. Walliker D, Quakyi IA, Wellems TE, McCutchan TF, Szarfman A, London WT, Corcoran LM, Burkot TR, Carter R: Genetic analysis of the human malaria parasite Plasmodium falciparum. Science 1987, 236:1661-1666.

14. Wellems TE, Walliker D, Smith CL, do Rosario VE, Maloy WL, Howard RJ, Carter R, McCutchan TF: A histidine-rich protein gene marks a linkage group favored strongly in a genetic cross of Plasmodium falciparum. Cell 1987, 49:633-642. 
15. Walker-Jonah A, Dolan SA, Gwadz RW, Panton LJ, Wellems TE: An RFLP map of the Plasmodium falciparum genome, recombination rates and favored linkage groups in a genetic cross. Mol Biochem Parasitol 1992, 51:313-320.

16. Baker J, Gatton ML, Peters J, Ho MF, McCarthy JS, Cheng Q: Transcription and expression of Plasmodium falciparum histidine-rich proteins in different stages and strains: implications for rapid diagnostic tests. PLOS One 2011, 6:e22593.

17. Gamboa D, Ho MF, Bendezu J, Torres K, Chiodini PL, Barnwell JW, Incardona S, Perkins M, Bell D, McCarthy J, Cheng Q: A large proportion of $\mathrm{P}$. falciparum isolates in the Amazon region of Peru lack pfhrp2 and pfhrp3: implications for malaria rapid diagnostic tests. PLoS One 2010, 5:e8091.

18. Houze S, Hubert V, Le Pessec G, Le Bras J, Clain J: Combined deletions of pfhrp2 and pfhrp3 genes result in Plasmodium falciparum malaria false-negative rapid diagnostic test. J Clin Microbiol 2011, 49:2694-2696.

19. Koita OA, Doumbo OK, Ouattara A, Tall LK, Konare A, Diakite M, Diallo M, Sagara I, Masinde GL, Doumbo SN, Dolo A, Tounkara A, Traore I, Krogstad DJ: False-negative rapid diagnostic tests for malaria and deletion of the histidine-rich repeat region of the hrp2 Gene. AmJTrop Med Hyg 2012, 86:194-198.

20. Mariette N, Barnadas C, Bouchier C, Tichit M, Menard D: Country-wide assessment of the genetic polymorphism in Plasmodium falciparum and Plasmodium vivax antigens detected with rapid diagnostic tests for malaria. Malar J 2008, 7:219.

21. Baker J, McCarthy J, Gatton M, Kyle DE, Belizario V, Luchavez J, Bell D, Cheng $\mathrm{Q}$ : Genetic diversity of Plasmodium falciparum histidine-rich protein 2 (PfHRP2) and its effect on the performance of PfHRP2-based rapid diagnostic tests. J Infect Dis 2005, 192:870-877.

22. Baker J, Ho MF, Pelecanos A, Gatton M, Chen N, Abdullah S, Albertini A, Ariey F, Barnwell J, Bell D, Cunningham J, Djalle D, Echeverry DF, Gamboa D, Hii J, Kyaw MP, Luchavez J, Membi C, Menard D, Murillo C, Nhem S, Ogutu B, Onyor P, Oyibo W, Wang SQ, McCarthy J, Cheng Q: Global sequence variation in the histidine-rich proteins 2 and 3 of Plasmodium falciparum: implications for the performance of malaria rapid diagnostic tests. Malar J 2010, 9:129.

23. Dondorp AM, Fanello Cl, Hendriksen IC, Gomes E, Seni A, Chhaganlal KD, Bojang K, Olaosebikan R, Anunobi N, Maitland K, Kivaya E, Agbenyega T, Nguah SB, Evans J, Gesase S, Kahabuka C, Mtove G, Nadjm B, Deen J, Mwanga-Amumpaire J, Nansumba M, Karema C, Umulisa N, Uwimana A, Mokuolu OA, Adedoyin OT, Johnson WB, Tshefu AK, Onyamboko MA, Sakulthaew T, Ngum WP, Silamut K, Stepniewska K, Woodrow CJ, Bethell D, Wills B, Oneko M, Peto TE, von Seidlein L, Day NP, White NJ: Artesunate versus quinine in the treatment of severe falciparum malaria in African children (AQUAMAT): an open-label, randomised trial. Lancet 2010, 376:1647-1657.

24. Snounou G, Viriyakosol S, Zhu XP, Jarra W, Pinheiro L, do Rosario VE, Thaithong S, Brown KN: High sensitivity of detection of human malaria parasites by the use of nested polymerase chain reaction. Mol Biochem Parasitol 1993, 61:315-320.

25. Hendriksen ICE, Mwanga-Amumpaire J, von Seidlein L, Mtove G, White LJ, Olaosebikan R, Lee SJ, Tshefu AK, Woodrow CJ, Amos B, Karema C, Saiwaew S, Maitland K, Gomes E, Pan-Ngum W, Gesase S, Silamut K, Reyburn H, Joseph S, Chotivanich K, Fanello Cl, Day NPJ, White NJ, Dondorp AM: Diagnosing severe falciparum malaria in parasitaemic African children; a prospective evaluation of plasma PfHRP2 measurement. PLoS Med 2012, 9:e1001297.

26. Howard RJ, Uni S, Aikawa M, Aley SB, Leech JH, Lew AM, Wellems TE, Rener J, Taylor DW: Secretion of a malarial histidine-rich protein (Pf HRP II) from Plasmodium falciparum-infected erythrocytes. J Cell Biol 1986, 103:1269-1277.

27. Desakorn V, Dondorp AM, Silamut K, Pongtavornpinyo W, Sahassananda D, Chotivanich K, Pitisuttithum P, Smithyman AM, Day NP, White NJ: Stage-dependent production and release of histidine-rich protein 2 by Plasmodium falciparum. Trans R Soc Trop Med Hyg 2005, 99:517-524.

28. Desakorn V, Silamut K, Angus B, Sahassananda D, Chotivanich K, Suntharasamai P, Simpson J, White NJ: Semi-quantitative measurement of Plasmodium falciparum antigen PfHRP2 in blood and plasma. Trans R SoC Trop Med Hyg 1997, 91:479-483.
29. Biswas S, Tomar D, Rao DN: Investigation of the kinetics of histidine-rich protein 2 and of the antibody responses to this antigen, in a group of malaria patients from India. Ann Trop Med Parasitol 2005, 99:553-562.

30. Bejon P, Berkley JA, Mwangi T, Ogada E, Mwangi I, Maitland K, Williams T, Scott JA, English M, Lowe BS, Peshu N, Newton CR, Marsh K: Defining childhood severe falciparum malaria for intervention studies. PLoS Med 2007, 4:e251

31. Taylor TE, Fu WJ, Carr RA, Whitten RO, Mueller JS, Fosiko NG, Lewallen S, Liomba NG, Molyneux ME: Differentiating the pathologies of cerebral malaria by postmortem parasite counts. Nat Med 2004, 10:143-145.

32. Beare NA, Taylor TE, Harding SP, Lewallen S, Molyneux ME: Malarial retinopathy: a newly established diagnostic sign in severe malaria. AmJTrop Med Hyg 2006, 75:790-797.

33. Yeo TW, Lampah DA, Gitawati R, Tjitra E, Kenangalem E, Piera K, Price RN, Duffull SB, Celermajer DS, Anstey NM: Angiopoietin-2 is associated with decreased endothelial nitric oxide and poor clinical outcome in severe falciparum malaria. Proc Natl Acad Sci U S A 2008, 105:17097-17102.

34. Ochola LB, Marsh K, Lowe B, Gal S, Pluschke G, Smith T: Estimation of the sequestered parasite load in severe malaria patients using both host and parasite markers. Parasitology 2005, 131(Pt 4):449-458.

35. Manning L, Laman M, Stanisic D, Rosanas-Urgell A, Bona C, Teine D, Siba P, Mueller I, Davis TM: Plasma Plasmodium falciparum histidine-rich protein2 concentrations do not reflect severity of malaria in Papua new guinean children. Clin Infect Dis 2011, 52:440-446.

36. Lee N, Gatton ML, Pelecanos A, Bubb M, Gonzalez I, Bell D, Cheng Q, McCarthy JS: Identification of optimal epitopes for Plasmodium falciparum Rapid Diagnostic Tests that target histidine-rich proteins 2 and 3. J Clin Microbiol 2012, 50:1397-1405.

doi:10.1186/1475-2875-11-276

Cite this article as: Ramutton et al: Sequence variation does not confound the measurement of plasma PfHRP2 concentration in African children presenting with severe malaria. Malaria Journal 2012 11:276.

\section{Submit your next manuscript to BioMed Central and take full advantage of:}

- Convenient online submission

- Thorough peer review

- No space constraints or color figure charges

- Immediate publication on acceptance

- Inclusion in PubMed, CAS, Scopus and Google Scholar

- Research which is freely available for redistribution 